\title{
TESTING THE ACCURACY OF MEASURED VALUES IN CONTINUOUS LONG-TERM GEODETIC MONITORING
}

\author{
JAN VANĚČEK*, MARTIN ŠTRONER \\ Department of the special geodesy, Faculty of the Civil Engineering, Czech Technical University in Prague, \\ Thakurova 7, Prague 6, Czech Republic \\ * corresponding author: jan.vanecek.2@fsv.cvut.cz
}

AbStract. A geodetic measurement of shifts and deformations by a total station is a well-known and widespread used method. In this paper, an analysis of the accuracy and its changes over time of the measured values in continuous geodetic monitoring is presented. For the analysis, a set of data measured in the period of time between January 2006 to July 2010 was used. The main method of the analysis is a linear-harmonic function approximation.

Keywords: Measurement of displacements and deformations, Mean squared error adjustments, Linear and harmonic approximation, Total station, Slope stability.

\section{INTRODUCTION}

A geodetic monitoring or a measurements of shifts and deformations is the branch of geodesy, which is dedicated to measure the objects periodically over time e.g. dams, bridges, buildings, landslides etc. The principle of this monitoring is the measuring of observed points on the object and comparing their position with previous results regularly in time. Measuring of the shifts is also specified in standards, e. g. in the Czech Republic it is CSN 730405. This subject is widely described in [1].

The measurements of shifts cover many areas of surveying, e. g. sub-millimetre level measuring of structures (e.g. [2]), bridges monitoring (e.g. [3]), tunnel monitoring (e.g. 4]), historical buildings monitoring (e.g. [5]) and landslide monitoring (e.g. [6]) or vertical ground deformation monitoring (e.g. [7]). A geodetic monitoring can also be used in rescue operations [8].

A geodetic monitoring is usually realized by the terrestrial methods of measuring (e.g. 9]), methods of global navigation satellite systems (GNSS, e.g. [10, 11]) or complex monitoring systems consisting of geodetic [12] and geotechnical instruments [13]. Special applications of monitoring can require special methods of determining of the shifts, e. g. a terrestrial laser scanning [14, a photogrammetry [15] or a radar interferometry, which is suitable especially for measuring dynamic movements [16].

A special case is the continuous monitoring, where the measuring machine records the measured values 24 hours a day, 7 days a week and 365 days in the year. This procedure is used for monitoring of the specific structures or other objects that create a large risk of damage to lives and property. An example might be the monitoring of the slopes, which are vulnerable to a landslide (e.g. [17, 18]).

In the processing and evaluation of the results obtained, it is necessary to know the accuracy with which each of the variables are measured. On the one hand, there is the accuracy of the instrument that the manufacturer states and was, most likely, determined in a laboratory or a calibration base in good weather conditions, and on the other hand, there is the actual accuracy that the instrument is able to achieve in a particular situation for a long-term monitoring in the specific conditions of the site.

The majority of scientific works deal with determining the accuracy of the measurements according to the standard ISO 17123, before the measurement starts (described in e.g. [19] or [20]). This procedure is suitable for short-term measurements, when local conditions do not change a lot, but it is not suitable for long-term monitoring, when conditions of the site change in time.

This article deals with identifying and evaluating the accuracy of the measurements of the automatic total station during the monitoring of the stability of slopes in the brown coal mine.

\section{DESCRIPTION OF THE MONITORING SYSTEM}

The data that were used for the analysis of the accuracy of the measurements are from the monitoring system from the ČSA surface mine. The mine is situated in the North Bohemia under the Ore Mountains (WGS84: $50.5380206 \mathrm{~N}, 13.5254592 \mathrm{E}$ ). Measured data were obtained from the Severní energetická a.s., which owns the ČSA mine. Unfortunately, the data can not be linked without the agreement of the Severní energetická a.s.

The monitoring system consists of several parts, the main element, which is the automatic total station Leica TCR 2003A, observed and reference points and a management center. Total station is located in the middle of the mine in a protective shelter (see Fig. 1). The observed points are located on the slopes of the Ore Mountains and the reference points are located 


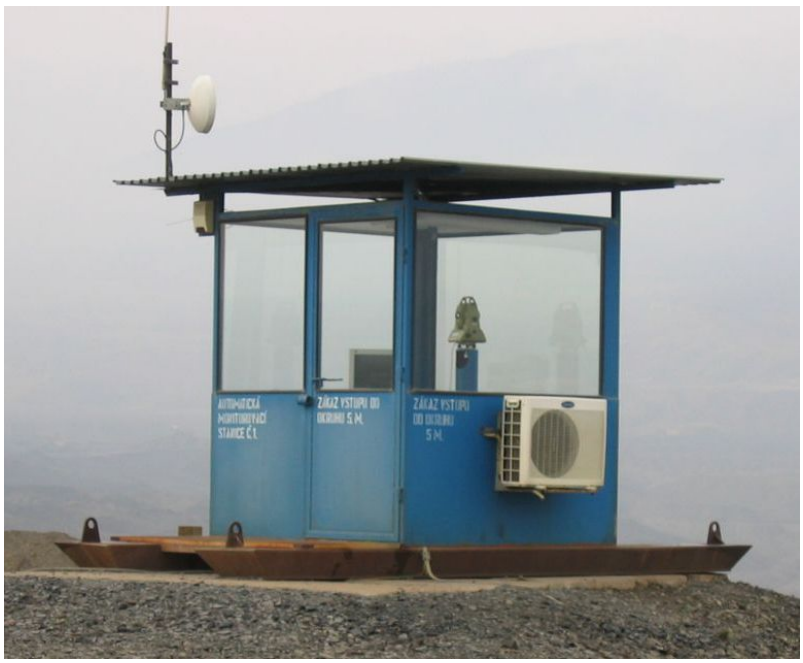

Figure 1. Total station in protective shelter.

on objects on the opposite side of the mine. The protective shelter for the total station is made from a metal with windows made of an ordinary glass and is equipped with a heating and an air conditioning (keep the internal temperature in the range of operating temperatures of the total station).

The total station was purchased especially for this purpose in 2005. The manufacturer declares the standard deviations of horizontal direction a zenith angle 0.15 mgon (measured in both faces) and the standard deviation of the slope distance $1 \mathrm{~mm}+1 \mathrm{ppm} \cdot D$.

The total station measures all observed and reference points every hour for 365 days a year with the exception of service outages and periods when visibility is not sufficient.

Outside temperature and atmospheric pressure are stored in addition to the standard measured values by the total station (a horizontal direction, a zenith angle and slope distance). There are calculated shifts for each round of measurements in the management center. The relevant employees of the company are automatically informed by a text message in the case of an imminent danger.

A detailed description of the monitoring system is given in 21. The measured values from the period from the beginning of 2006 to July 2010 were used for the analysis of the accuracy of the horizontal direction, the zenith angle and a slope distance.

\section{MATHEMATICAL BASIS \\ OF THE ANALYSIS OF THE ACCURACY OF THE MEASUREMENTS}

At first, an estimate of the accuracy of the measurements can be calculated from the measured values for an analysis of the accuracy. This estimate of the accuracy is based on the calculation of the accuracy from the differences between the consecutive measurements according to (1), which can be regarded as a pair of measurements. The estimate of the standard deviation of measurements is then calculated according to (2) for the specific interval (1 day, 7 days, 30 days, 90 days, etc.). The derivation of the calculation of the standard deviation for pairs of measurements is shown e. g. in [22].

Differences of pairs of measurements shall be calculated according to

$$
\Delta_{i}=l_{i+1}-\left.l_{i}\right|_{\Delta_{i} \leq \Delta_{M}},
$$

where $l_{i}$ is the measurement in the time $i$ and the calculated difference shall apply in next step of the calculation on condition that the calculated difference is less than the specified limit $\Delta_{M}$.

An estimate of the standard deviation is then

$$
s_{l}=\sqrt{\frac{\sum_{j=1}^{n} \Delta_{j}^{2}}{2 n}},
$$

where $n$ is the number of the differences of measurements in the given time interval (e. g. one day -24 hours). The calculated standard deviation is assigned a time index that equals to the center of the center time interval, which is more important for longer time intervals such as 30 or 90 days.

The basis of the analysis of the accuracy of the measurements comes out of the above calculated standard deviations for each day for the whole of the reference period (i.e., January 2006-July 2010). The analysis was made by the approximation of computed values of the standard deviations specific curve (L-H function), which contains the linear and harmonic part and its equation is the following:

$$
y=a+b x+c \sin \left(\frac{2 \pi x}{t}+d\right),
$$

where $a$ is the absolute coefficient, $b$ is a linear coefficient (slope of the regression), $c$ is an amplitude of the harmonics part, $d$ is a phase shift and $t$ is the period. This function was chosen because of the linear trend that indicates a worsening of the accuracy of the measurements in time and the harmonic part describes the periodic changes of the accuracy during the year, depending on the temperature and other weather conditions variation.

The coefficients of $\mathrm{L}-\mathrm{H}$ function have been obtained by an approximation using method of least squares. The calculation was very sensitive to the choice of the approximate unknowns due to the large number of standard deviations and their similar size. The same weight was assigned to all standard deviations in calculation.

Linear coefficient of the $\mathrm{L}-\mathrm{H}$ function was further tested by the tests of statistical hypotheses, whether the data comprise linear trend, namely whether the calculated coefficient $b$ corresponds to the expected value of $\Theta$. In this case, the premise is that the parameter $b$ has a value $\Theta=0$. It means that the standard deviation has no trend. Null hypothesis will be of the form:

$$
H_{0}: b=\Theta \Rightarrow b=0 .
$$




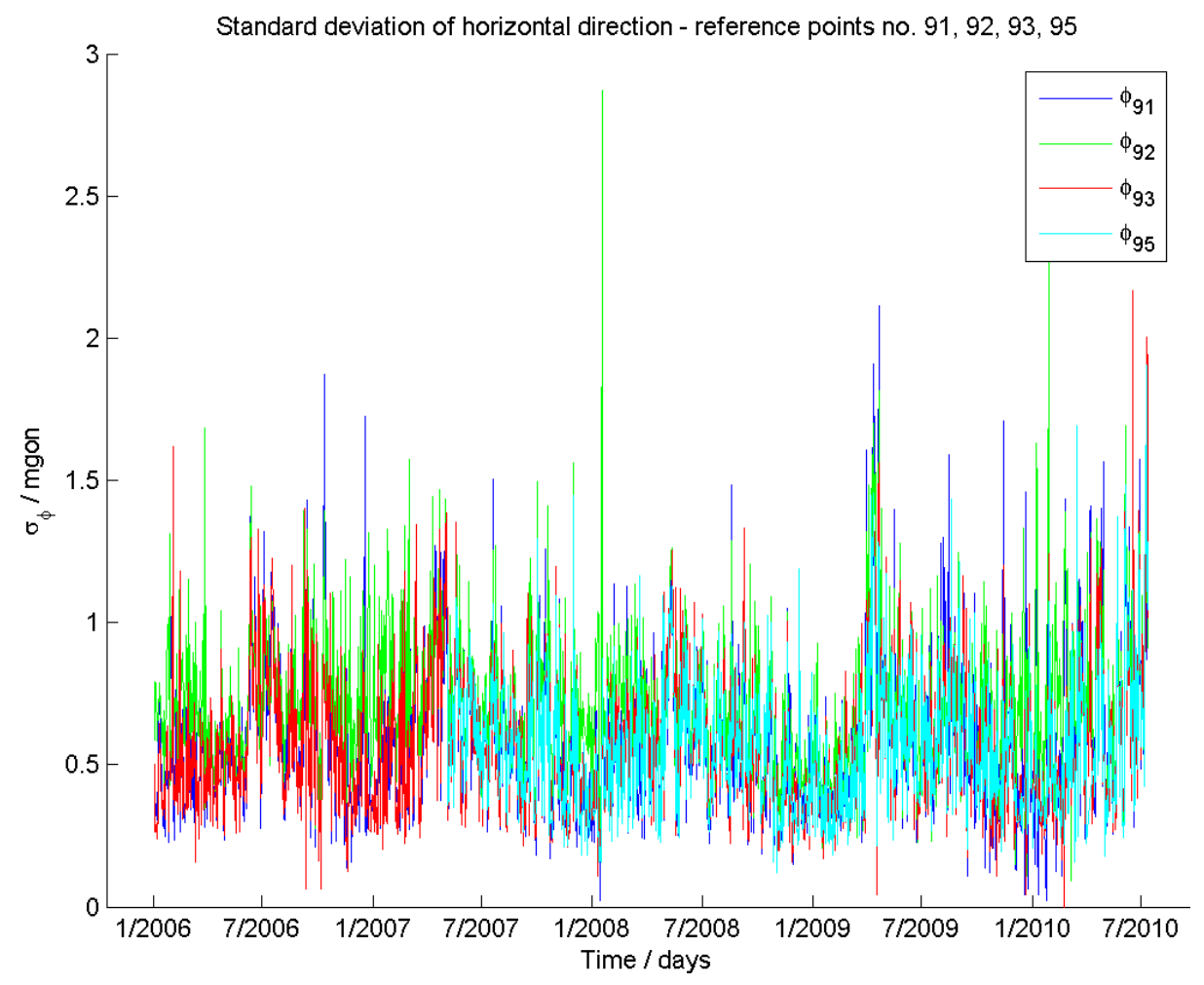

Figure 2. Standard deviation of horizontal direction for all tested reference points.

Testing can be done on the base of the two test criteria. In the first case, the tested value $F$ has the Fisher distribution of probability with $(n-k)$ degrees of freedom

$$
F=\frac{(b-\Theta)^{2}}{\sigma_{b}^{2}} .
$$

In the second case, the tested value $T$ has the Student T-distribution of the probability with $(n-k)$ degrees of freedom

$$
T=\frac{b-\Theta}{\sigma_{b}} .
$$

Critical values $F_{\alpha}$ and $T_{\alpha / 2}$ are determined from tables, or by calculation for the two-sided test at a significance level $\alpha$. The null hypothesis will be rejected if $F>F_{\alpha}$ or $|T|>T_{\alpha / 2}$.

The second step of the analysis was a comparison of the L-H curve of the standard deviation of the measurements with the L-H curve of the temperature of the air, which was determined by the same calculation as the L-H curve of the standard deviation of the measurements from the equation (3) of the daily average air temperature values. The premise of this comparison is that the accuracy of the measurements depends on the temperature changes during the year.

The third step in the analysis of the accuracy is the calculation of the accuracy for a longer time intervals and their comparison. These time intervals were chosen in the lengths of 7 days, 30 days and 90 days. The analysis was carried out for the reference points 91 , 92, 93 and 95. Reference point no. 94 was not tested because it was measured for a short period of time in comparison with the other points.

\section{Results OF THE ANALYSiS OF THE ACCURACY OF THE HORIZONTAL DIRECTIONS}

Analysis of the accuracy of the horizontal directions was carried out according to the process described in the previous chapter. In the calculation of the differences of pairs of measurements according to (1), the size of the limit difference $\Delta_{M}$ was chosen at the value of 0.01 gon. The choice was not based on the accuracy of the horizontal direction specified by the manufacturer of the device (standard deviation to calculate the limit difference), because the accuracy of the manufacturer may not be retained in the specific conditions of the mine. Therefore, the size of the marginal difference was determined experimentally from the graphs of measured values of the horizontal direction.

In Fig. 2, the calculated daily standard deviation for all tested reference points is shawn. It is seen that the progress of the size accuracy is approximately the same for all points, only in rare cases, there are outliers.

At first, approximation of daily standard deviations of the horizontal direction was made by using the L-H function as an approximation curve. The computed values of the important coefficients of approximation curves for individual reference points are listed in Table 1. There is not an coefficient $a$ that is an absolute part of the L-H function (approximate mean value), and a coefficient $d$, which is a phase shift of the periodic part of the function. Standard deviations and the approximation curve of measurements for the 


\begin{tabular}{lcccc}
\hline \multirow{2}{*}{ Coefficient } & \multicolumn{4}{c}{ Reference point } \\
\cline { 2 - 5 } & $\mathbf{9 1}$ & $\mathbf{9 2}$ & $\mathbf{9 3}$ & $\mathbf{9 5}$ \\
\hline$b \quad\left[\frac{\mathrm{mgon}}{\text { year }}\right]$ & 0.01 & -0.01 & 0.002 & 0.01 \\
$\sigma_{b}$ & $3 \cdot 10^{-6}$ & $3 \cdot 10^{-6}$ & $3 \cdot 10^{-6}$ & $3 \cdot 10^{-6}$ \\
\hline$c \quad[$ mgon $]$ & 0.12 & 0.05 & 0.13 & 0.12 \\
$\sigma_{c}$ & $2 \cdot 10^{-6}$ & $2 \cdot 10^{-6}$ & $2 \cdot 10^{-6}$ & $4 \cdot 10^{-6}$ \\
\hline$t \quad[$ day $]$ & 366.1 & 380.1 & 362.1 & 368.8 \\
$\sigma_{t}$ & 0.001 & 0.008 & 0.001 & 0.002 \\
\hline
\end{tabular}

TABLE 1. Important coefficients of approximation curves of horizontal direction standard deviations.

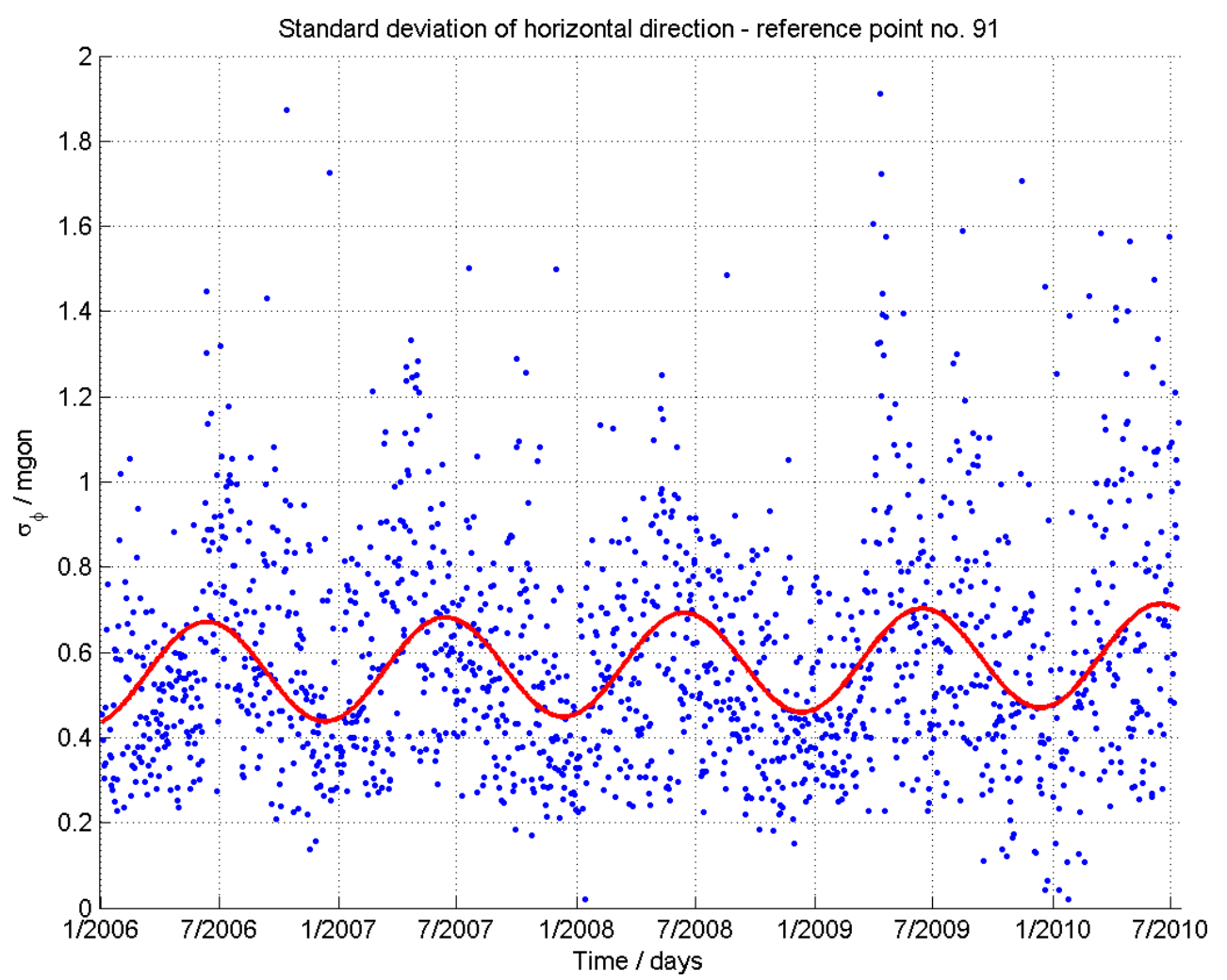

FiguRE 3. Approximation curve of the standard deviations of horizontal direction - reference point 91.

reference point 91 are shown in Fig. 3

It can be clearly seen from the chart that the values of the standard deviation lie between the values 0.2 and 1.0 mgon, and that the approximation curve has a small amplitude. The mean value lies between the values 0.5 and 0.6 mgon. The value of the linear trend obtained from Table 1 is 0.01 mgon per year, which is a value that can be neglected regardless of the fact that the results of the tests of statistical hypotheses confirm the linear trend.

Next step of the analysis is a comparison of the approximation curve of the temperature and the approximation curve of the standard deviations of the horizontal direction. The comparison was carried out graphically and the result is in Fig. 4. There is an apparent dependence of the standard deviation of the horizontal direction on the average daily air temperature that can be seen from this chart. When the average daily temperature increases, the value of the standard deviation of the horizontal direction increases too. The length of the period is a year that is apparent in the chart and it is listed in Table 1 .

The last chart in Fig. 5 shows a comparison of the standard deviations of the horizontal direction that are calculated for a longer time intervals. We can see that even in long time intervals there are periodic changes. There is still a noticeable slight increase of the size of the standard deviation at the end of the reference period.

A part of the analysis was the calculation of the average standard deviations of the horizontal direction for all the reference points. The average standard deviations were calculated using the root mean square of the daily standard deviations of the horizontal directions. The average standard deviations are listed in Table 3. There are also the smallest and the largest daily standard deviations and numbers of the daily standard deviations in Table 3 


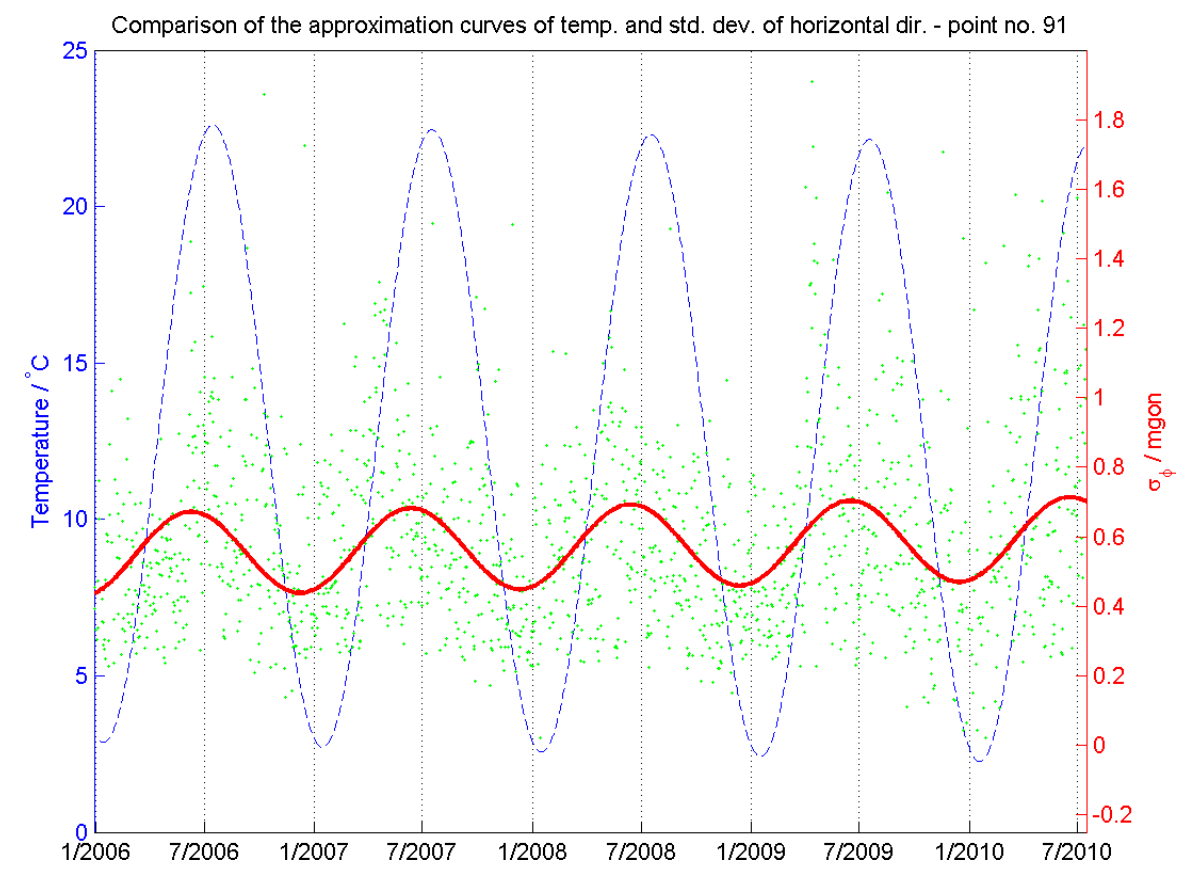

FigURE 4. Comparison of the approximation curves of the temperature and the standard deviation of the horizontal direction - reference point 91 .

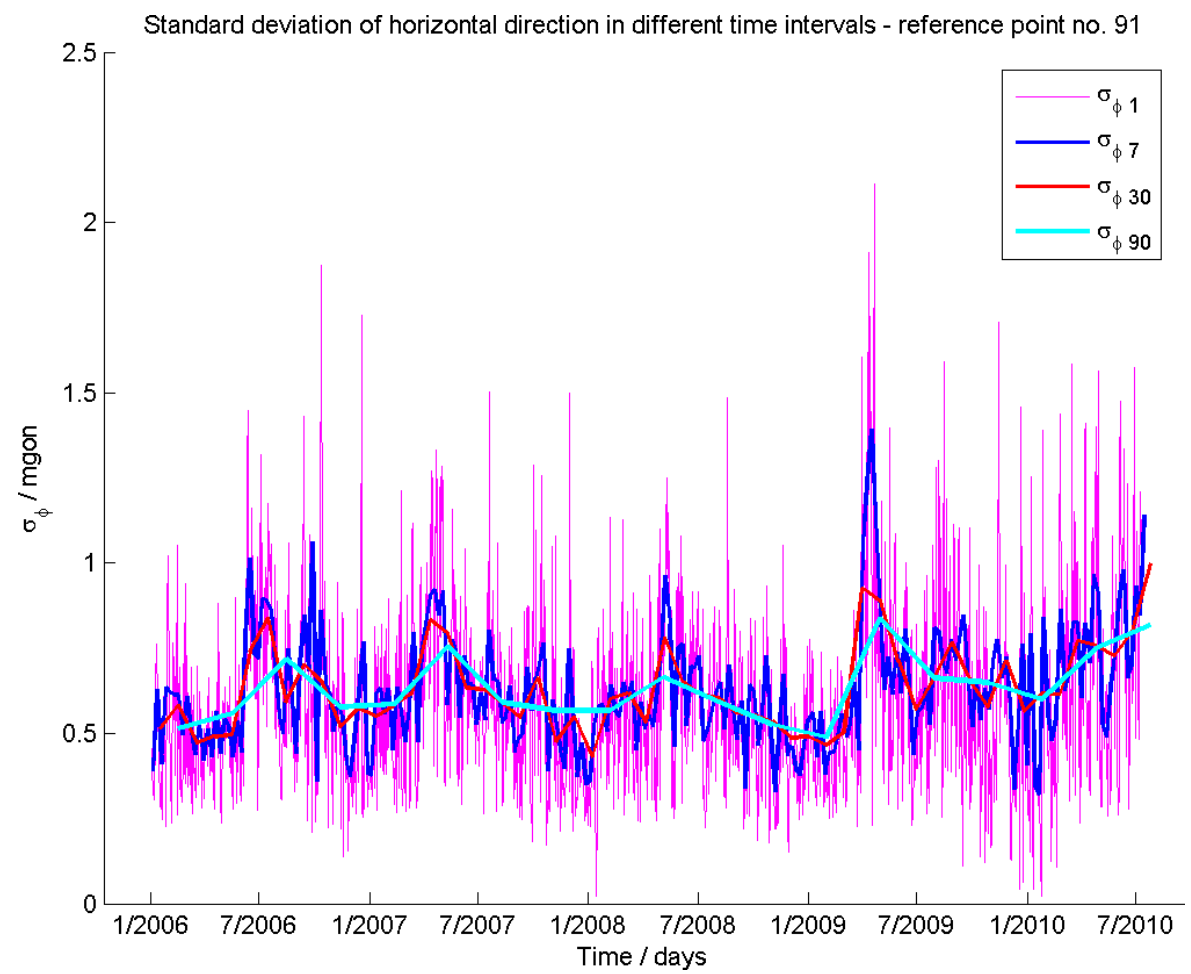

FiguRE 5. Standard deviations of the horizontal direction in different time intervals - reference point 91.

\begin{tabular}{lrrrr}
\hline \multicolumn{5}{c}{ Reference point } \\
& \multicolumn{1}{c}{$\mathbf{9 1}$} & $\mathbf{9 2}$ & $\mathbf{9 3}$ & \multicolumn{1}{c}{$\mathbf{9 5}$} \\
\hline$F$ & 10369984 & 9567181 & 590403 & 28835683 \\
$F_{\alpha=0.5}$ & 4 & 4 & 4 & 4 \\
\hline$T$ & 3220 & -3093 & 768 & 5370 \\
$T_{\alpha=0.25}$ & 2 & 2 & 2 & 2 \\
\hline$n^{\prime}$ & 1574 & 1588 & 1605 & 1132 \\
\hline
\end{tabular}

TABLE 2. Results of the tests of the statistical hypothesis. 


\begin{tabular}{lccccc}
\hline & \multicolumn{4}{c}{ Reference point } \\
\cline { 2 - 5 } & $\mathbf{9 1}$ & $\mathbf{9 2}$ & $\mathbf{9 3}$ & $\mathbf{9 5}$ \\
\hline$\overline{\sigma_{\varphi}}\left[\begin{array}{l} \\
\end{array}\right.$ & 0.66 & 0.75 & 0.63 & 0.61 \\
$\min \sigma_{\varphi}[$ mgon] & 0.02 & 0.09 & 0 & 0.12 \\
$\max \sigma_{\varphi}[$ mgon] & 2.11 & 2.87 & 2.17 & 1.9 \\
\hline$n$ & 1579 & 1593 & 1610 & 1137 \\
\hline
\end{tabular}

TABLE 3. Average daily standard deviations of the horizontal direction, min./max. values.

\begin{tabular}{|c|c|c|c|c|}
\hline \multirow[t]{2}{*}{ Coefficient } & \multicolumn{4}{|c|}{ Reference point } \\
\hline & 91 & 92 & 93 & 95 \\
\hline $\begin{array}{l}B \quad\left[\frac{\text { mgon }}{\text { year }}\right] \\
\sigma_{B}\end{array}$ & $\begin{array}{l}-0.01 \\
2 \cdot 10^{-5}\end{array}$ & $\begin{array}{l}0.002 \\
4 \cdot 10^{-7}\end{array}$ & $\begin{array}{l}0.0005 \\
5 \cdot 10^{-7}\end{array}$ & $\begin{array}{l}0.002 \\
5 \cdot 10^{-7}\end{array}$ \\
\hline $\begin{array}{ll}c & \text { [mgon] } \\
\sigma_{c} & \\
\end{array}$ & $\begin{array}{l}0.03 \\
4 \cdot 10^{-5}\end{array}$ & $\begin{array}{l}0.04 \\
7 \cdot 10^{-7}\end{array}$ & $\begin{array}{l}0.01 \\
4 \cdot 10^{-6}\end{array}$ & $\begin{array}{l}0.03 \\
2 \cdot 10^{-7}\end{array}$ \\
\hline $\begin{array}{l}T \quad \text { [day] } \\
\sigma_{T}\end{array}$ & $\begin{array}{r}390.6 \\
0.04\end{array}$ & $\begin{array}{l}391.8 \\
0.0001\end{array}$ & $\begin{array}{r}424.4 \\
0.10\end{array}$ & $\begin{array}{r}408.2 \\
0.003\end{array}$ \\
\hline
\end{tabular}

TABLE 4. Important coefficients of the approximation curves of the zenith angle standard deviations.

\section{ANALYSiS}

\section{OF THE ACCURACY OF THE ZENITH ANGLE}

Analysis of the accuracy of the zenith angle is based on the same approach as the previous analysis of the accuracy of the horizontal direction. Even in this case, the limit difference $\Delta_{M}$ was chosen as the value of 0.01 gon during the calculation of the differences of pairs of measurements (1), for the same reasons that were described in the section dedicated to accuracy of the horizontal direction.

Fig. 6 shows the calculated daily standard deviations for all tested reference points from which it can be seen that the progress of the size accuracy is similar for all points, only for reference point 91 are the values of the standard deviations lower than the average for the other points. In comparison with the horizontal direction, there are also more outlying values, but due to the considerably greater influence of the refraction in the vertical direction, it can be expected.

Firstly the approximation of the calculated standard deviations for each day was done using the $\mathrm{L}-\mathrm{H}$ function. The values of the important coefficients of curves for all tested reference points are listed in Table 4. Chart of values of standard deviations and the approximation curve for the reference point 91 is shown in Fig. 7.

Fig. 7 shows that the large part of values of the standard deviation lies in the range from 0.2 to 0.8 mgon. The approximation curve is very flat and the mean value is approximately $0.5 \mathrm{mgon}$. The value of the linear trend given in Table 4 is -0.01 mgon per year (the highest value of all the reference points). In this situation, the value of the linear trend is so small that it can be neglected, despite the fact that the linear trend can be considered for the proven based on the results of the tests of statistical hypotheses listed in Table 5 .

Furthermore, it is obvious from the approximation curve in Fig. 7 that a period of harmonious part and the $\max / \mathrm{min}$ of the curve do not correspond to the seasons. It is obvious from Table 4 that the value of the period is around 400 days.

The next step of the analysis was a comparison of the calculated approximation curves of the standard deviations of the zenith angle with the approximation curve of the air temperature. The comparison was carried out in a graphical way. The result is shown in Fig. 8 We can conclude the same thing as from the Fig. 7. The data may contain a certain period, but its dependence on the temperature can't be proved. In the case of the zenith angle the size of the standard deviation is probably mainly affected by influences other than the temperature of the air (direct sunlight, wind, precipitation, etc.).

The graph clearly shows that even in longer time intervals, there are noticeable periodic changes of the size of the standard deviation. However, for the interval of 90 days, the curve is almost flat.

Similarly as for the horizontal direction, the average standard deviation of the zenith angle was calculated for all reference points, using the root mean square of the daily standard deviations. The average standard deviations are listed in Table 6, which also contains the smallest and the largest daily standard deviation and a number of daily standard deviations used for the analysis. 


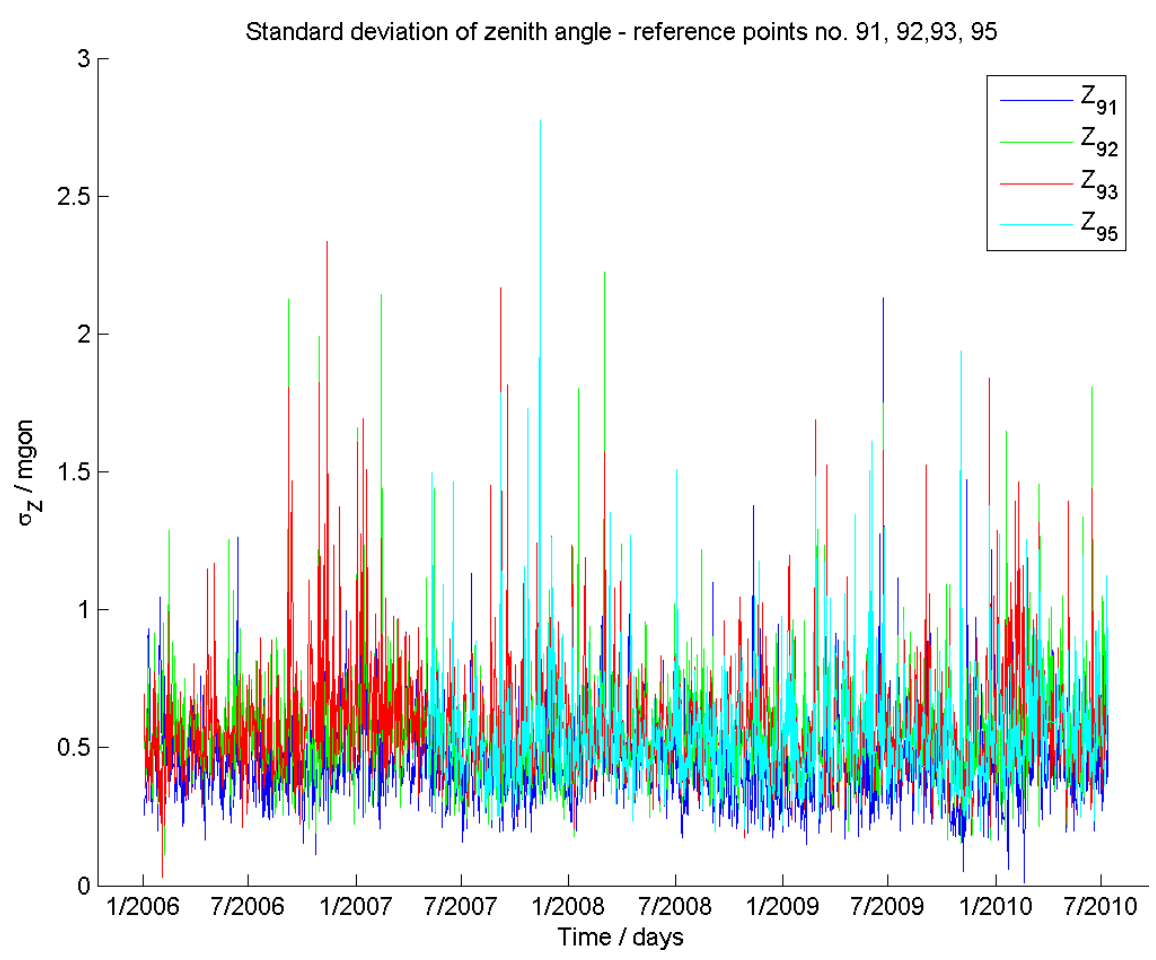

Figure 6. Calculated daily standard deviations of the zenith angle for all reference points.

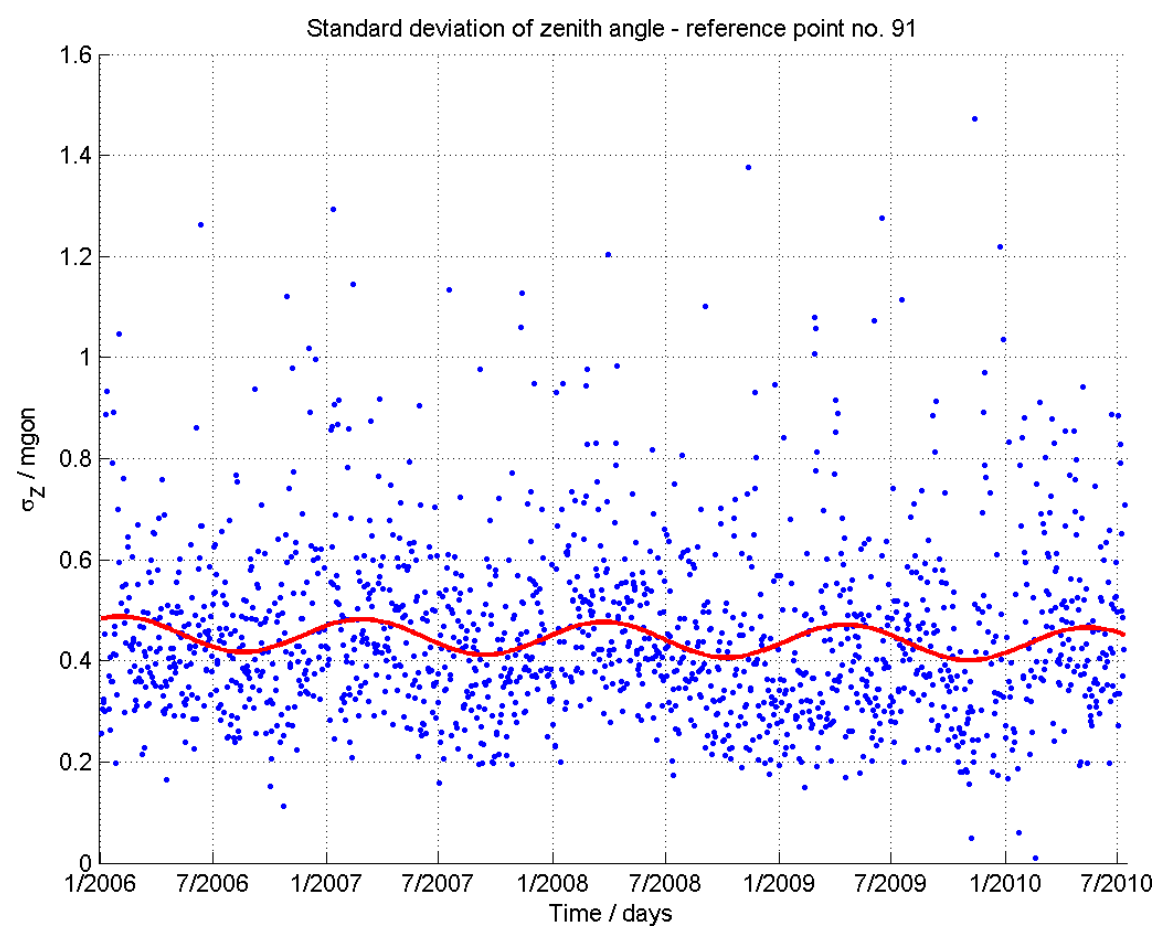

FiguRE 7. Values of standard deviation of the zenith angle and approximation curve - reference point 91.

\begin{tabular}{lrrrr}
\hline & \multicolumn{4}{c}{ Reference point } \\
\cline { 2 - 5 } & \multicolumn{1}{c}{$\mathbf{9 1}$} & $\mathbf{9 2}$ & $\mathbf{9 3}$ & \multicolumn{1}{c}{$\mathbf{9 5}$} \\
\hline$F$ & 67349 & 22528972 & 794872 & 11338453 \\
$F_{\alpha=0.5}$ & 4 & 4 & 4 & 4 \\
\hline$T$ & -260 & 4746 & 892 & 3367 \\
$T_{\alpha=0.25}$ & 2 & 2 & 2 & 2 \\
\hline$n^{\prime}$ & 1574 & 1588 & 1605 & 1132 \\
\hline
\end{tabular}

TABLE 5. Results of the tests of the statistical hypothesis. 


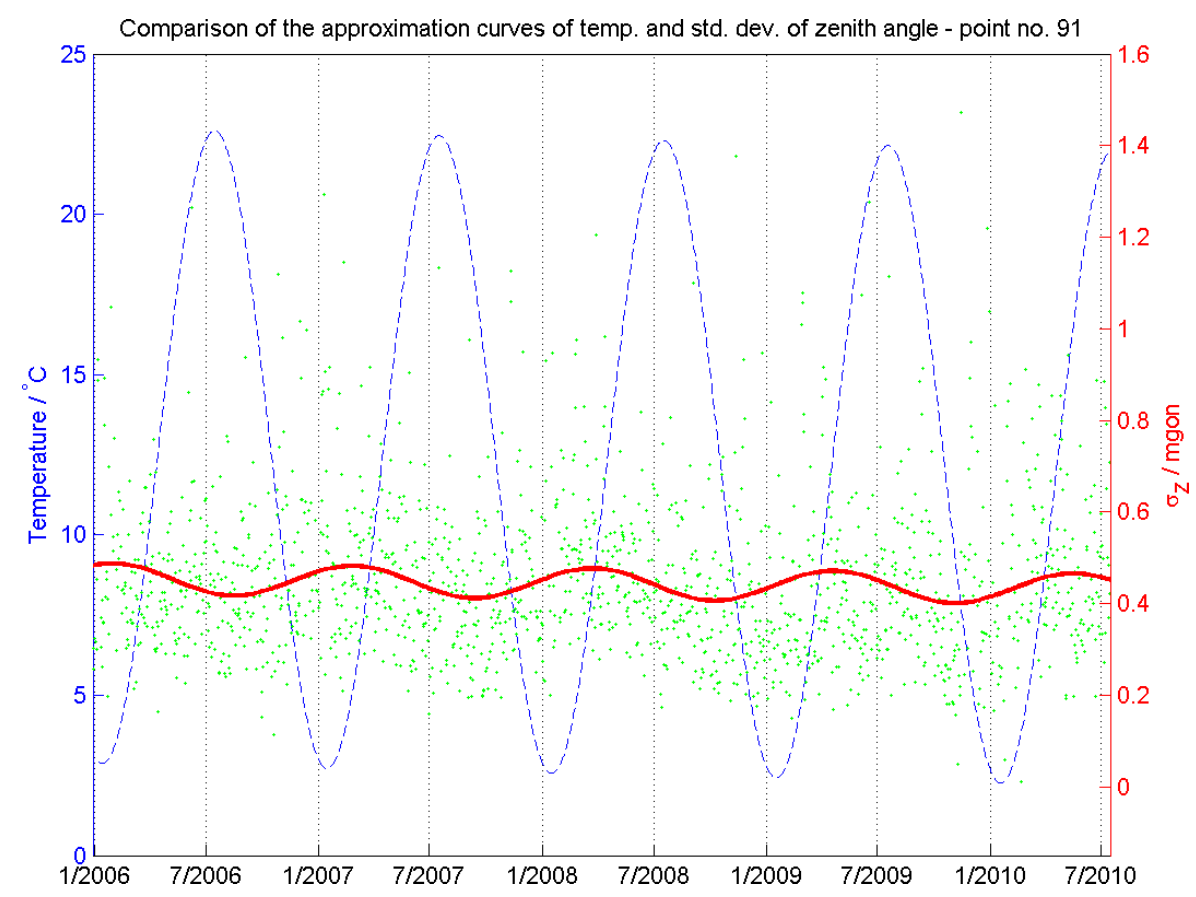

Figure 8. Comparison of the approximation curves of the temperature and standard deviation of the horizontal direction - reference point 91 .

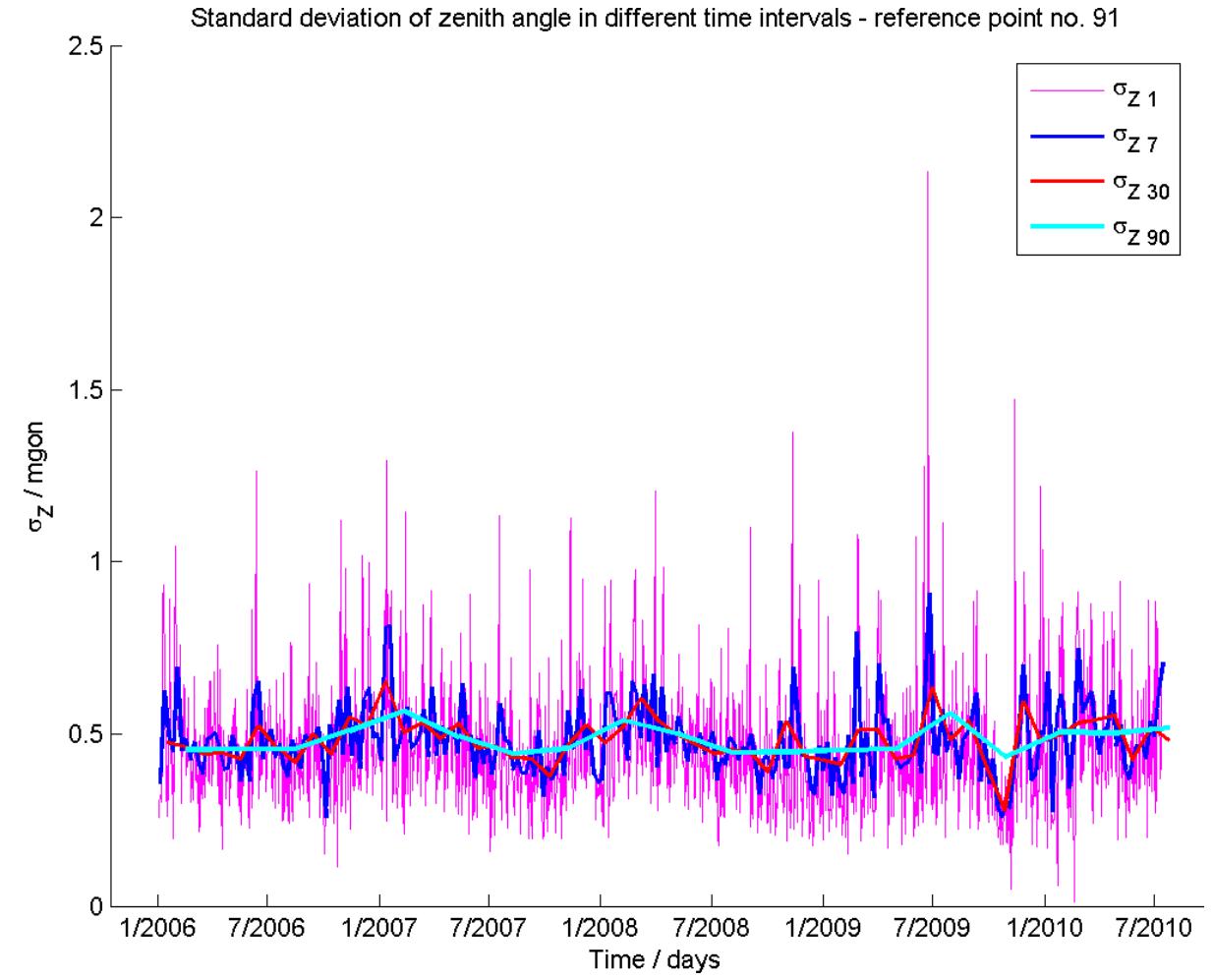

Figure 9. Standard deviations of the zenith angle in different time intervals - reference point 91.

\begin{tabular}{lccccc}
\hline & \multicolumn{4}{c}{ Reference point } \\
\cline { 3 - 6 } & $\mathbf{9 1}$ & $\mathbf{9 2}$ & $\mathbf{9 3}$ & $\mathbf{9 5}$ \\
\hline$\overline{\sigma_{Z}}$ & {$[$ [mgon] } & 0.49 & 0.6 & 0.63 & 0.59 \\
$\min \sigma_{Z}$ & {$[$ mgon] } & 0.01 & 0.11 & 0.03 & 0.2 \\
$\max \sigma_{Z}$ & {$[$ mgon] } & 2.13 & 2.22 & 2.33 & 2.77 \\
\hline$n$ & 1579 & 1593 & 1610 & 1137 \\
\hline
\end{tabular}

TABLE 6. Average daily standard deviations of the zenith angle and min./max. values. 


\begin{tabular}{|c|c|c|c|c|}
\hline \multirow[t]{2}{*}{ Coefficient } & \multicolumn{4}{|c|}{ Reference point } \\
\hline & 91 & 92 & 93 & 95 \\
\hline$B \quad\left[\frac{\mathrm{mm}}{\text { vear }}\right]$ & 0.06 & 0.001 & 0.03 & 0.02 \\
\hline$\sigma_{B}$ & $1 \cdot 10^{-7}$ & $5 \cdot 10^{-7}$ & $1 \cdot 10^{-6}$ & $2 \cdot 10^{-7}$ \\
\hline$c \quad[\mathrm{~mm}]$ & 0.19 & 0.36 & 0.18 & 0.19 \\
\hline$\sigma_{c}$ & $2 \cdot 10^{-6}$ & $1 \cdot 10^{-6}$ & $2 \cdot 10^{-5}$ & $7 \cdot 10^{-7}$ \\
\hline$T \quad$ [day $]$ & 367.1 & 365.6 & 367.6 & 373.1 \\
\hline$\sigma_{T}$ & 0.0001 & 0.0001 & 0.001 & 0.0002 \\
\hline
\end{tabular}

TABLE 7. Important coefficients of the approximation curves of the standard deviations of the slope distance.

\section{AnAlysis OF THE ACCURACY OF THE SLOPE DISTANCE}

The last quantity, directly measured by the total station, is the slope distance. The analysis of the accuracy was carried out using the same process as the previous analysis of the accuracy of the horizontal direction and the zenith angle. in this case, the limit difference was selected as the value $\Delta_{M}=0.007 \mathrm{~m}$ for the calculation of the differences of pairs of measurements (1).

The choice of the limit difference was based on the same assumptions as in the case of the horizontal direction and the zenith angle. The standard deviation of the slope distance, according to the manufacturer, is $\sigma_{S}=1 \mathrm{~mm}+1 \mathrm{ppm} D$ ( $D$ is measured distance). The standard deviation of the slope distance to the reference point 91 is then $2.3 \mathrm{~mm}$. The limit difference can be determined as $\Delta_{M}=\sigma_{S} \cdot \sqrt{2} \cdot u_{p}\left(u_{p}=2\right.$ for probability $95 \%, u_{p}$ is the coefficient of the standard normal distribution). The calculated value of the limit difference is then $6.5 \mathrm{~mm}$ that was rounded up to $7 \mathrm{~mm}$, and used in (1), because there was a minimum of occurrences of a larger difference than the limit difference, in the experimental testing of measurements.

The calculated daily standard deviations of the slope distance for all tested reference points are shown in Fig. 10. It is seen that the progress of the accuracy is similar for all points, only for the point 92, the standard deviation is slightly higher than for the other points. This is caused probably a stabilization of the reference point 92 , which is high lattice tower.

The first step of the analysis was, again, an approximation of the calculated daily standard deviations by the L-H function. The calculated values of important coefficients of the approximation curves are listed in Table 10. Chart of the values of the standard deviations and the approximation curve for the reference point 91 is shown in Fig. 11

From the graph in Fig. 11, it can be seen that the values of the standard deviation are almost all located in the interval with the upper limit of the value of $2.5 \mathrm{~mm}$, which is slightly more than the manufacturer declared standard deviation. In this case, the approximation curve is not flat, there is an obvious linear trend. The value of the linear trend for the reference point 91 is, as can be seen in Table 7, $0.06 \mathrm{~mm}$ a year (the highest of the tested reference points). The linear trend can be considered as proven, based on the results of the tests of the statistical hypotheses listed in Table 8. But the value of the linear trend is very small and it is possible to neglect this trend for a given purpose. It is important to note that a positive linear trend reflects the deteriorating accuracy of the slope distance. There is a visible decrease of the blue dots scattering (the value of the standard deviation of the slope distance) over time in Fig. 11. This phenomenon is observable for most of the slope distance, for the horizontal direction, it is less noticeable, and for the zenith angle, it is practically not observable.

The next step of the analysis was a comparison of the calculated approximation curves of the standard deviations of the slope distance with the approximation curve of the air temperature. The comparison was carried out in a graphical way. The result is shown in Fig. 12, This figure expresses the same conclusion that is obvious from the Fig. 11. The size of the standard deviation of the slope distance is dependent on the temperature of the air. The standard deviation of the slope distance increases in the warm months, while reaching minimum values in the winter. Values of the period bring the same conclusion as graph. The lenght of the period is about 367 days (listed in Table 7).

The last graph in Fig. 13 expresses a comparison of the standard deviation of the slope distance calculated for different time intervals. We can see in Fig. 13 that noticeable periodic changes of the value of the standard deviation remain even in longer time intervals and that there is a slight increase of the value of the standard deviation since the beginning of 2009 .

Similarly, as in the section on horizontal direction and in the section on zenith angle, the average standard deviation of the slope distance was calculated for all the reference points by using the root mean square of the daily standard deviations. The averages of the standard deviations are listed in Table 9. Table 9 also contains the smallest and the largest daily standard deviation of the slope distance and the number of daily standard deviations used for the 


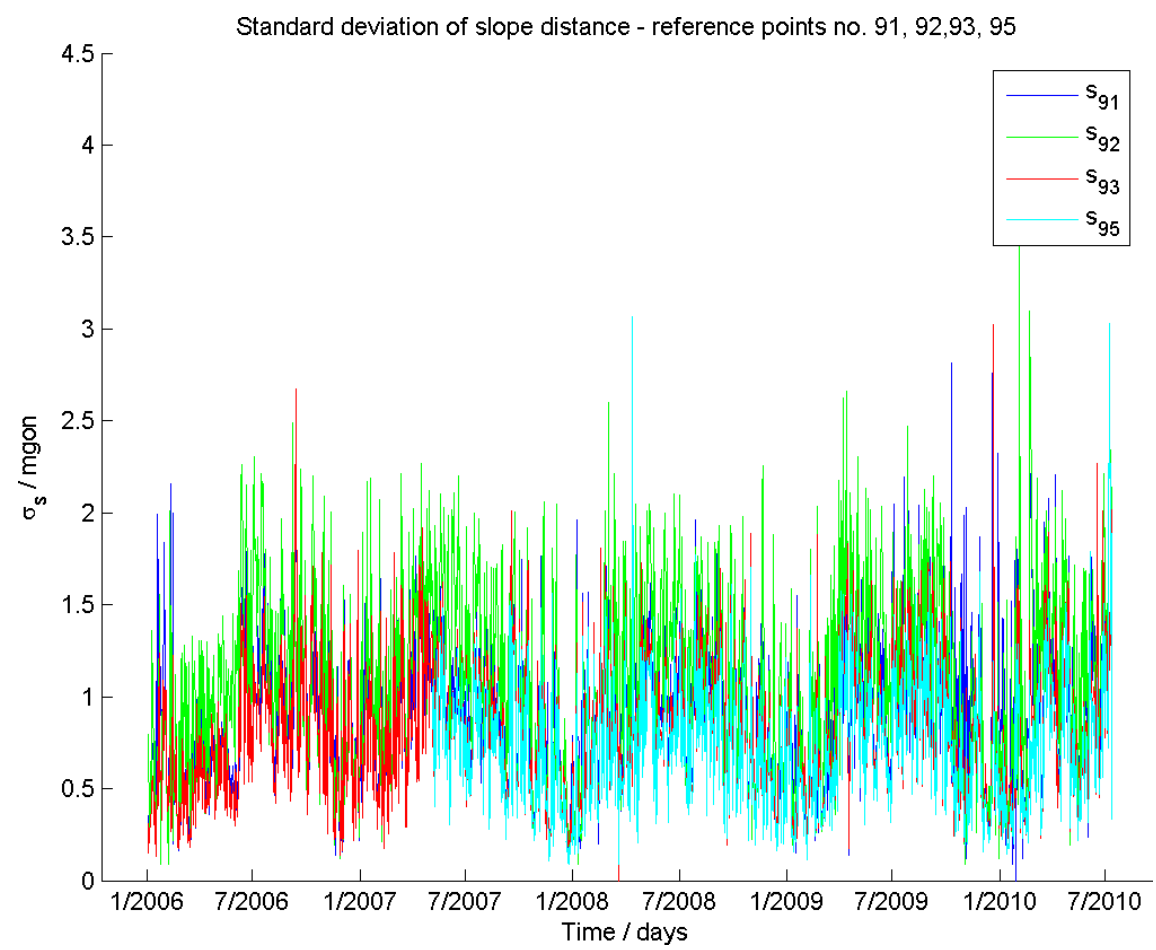

Figure 10. Calculated daily standard deviations of the slope distance for all reference points.

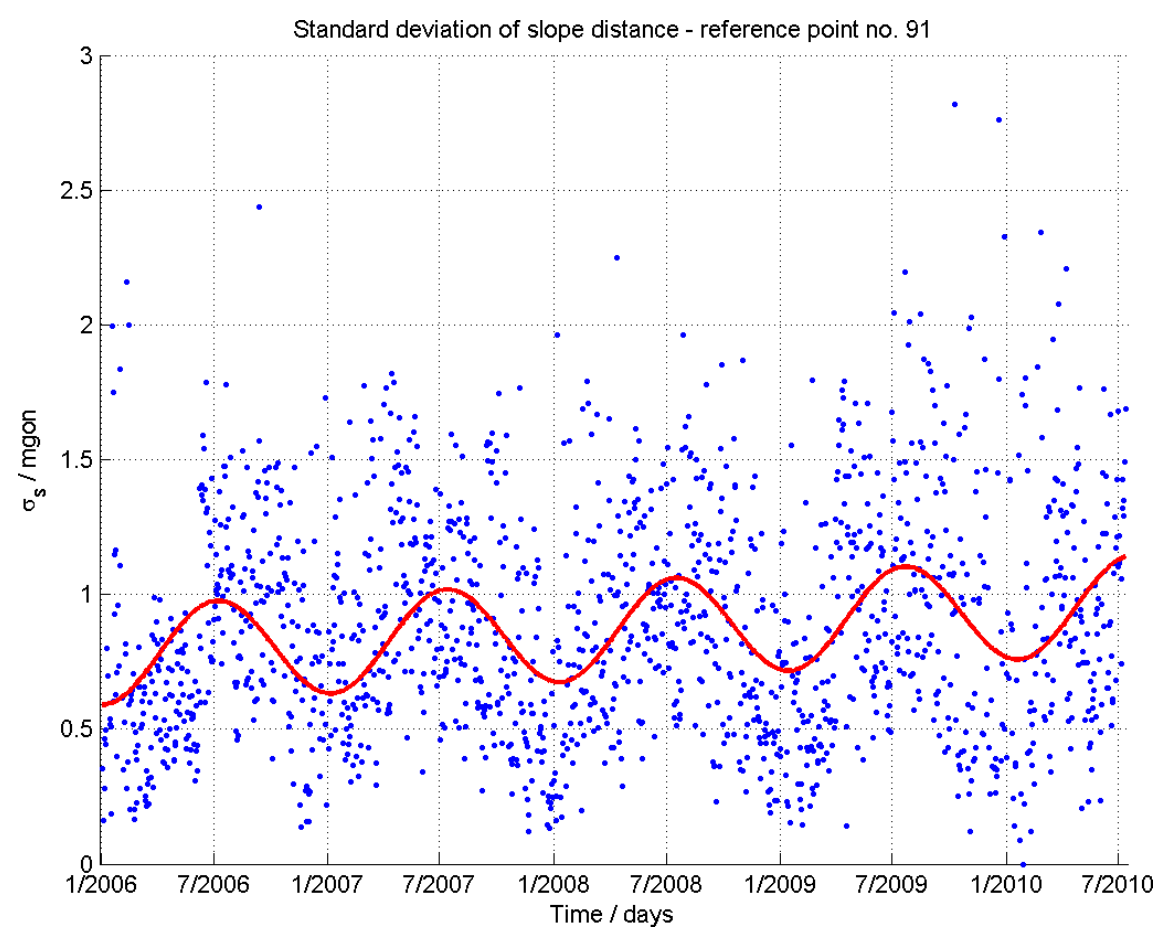

FIGURE 11. Approximation curve of the standard deviations of the slope distance for reference point 91.

\begin{tabular}{lrrrr}
\hline \multicolumn{5}{c}{ Reference point } \\
& \multicolumn{1}{c}{$\mathbf{9 1}$} & $\mathbf{9 2}$ & $\mathbf{9 3}$ & \multicolumn{1}{c}{$\mathbf{9 5}$} \\
\hline$F$ & 173610514013 & 2970776 & 883731125 & 10549655517 \\
$F_{\alpha=0.5}$ & 4 & 4 & 4 & 4 \\
\hline$T$ & 416666 & 1724 & 29728 & 102712 \\
$T_{\alpha=0.25}$ & 2 & 2 & 2 & 2 \\
\hline$n^{\prime}$ & 1574 & 1588 & 1605 & 1132 \\
\hline
\end{tabular}

TABLE 8. Results of the tests of the statistical hypothesis. 


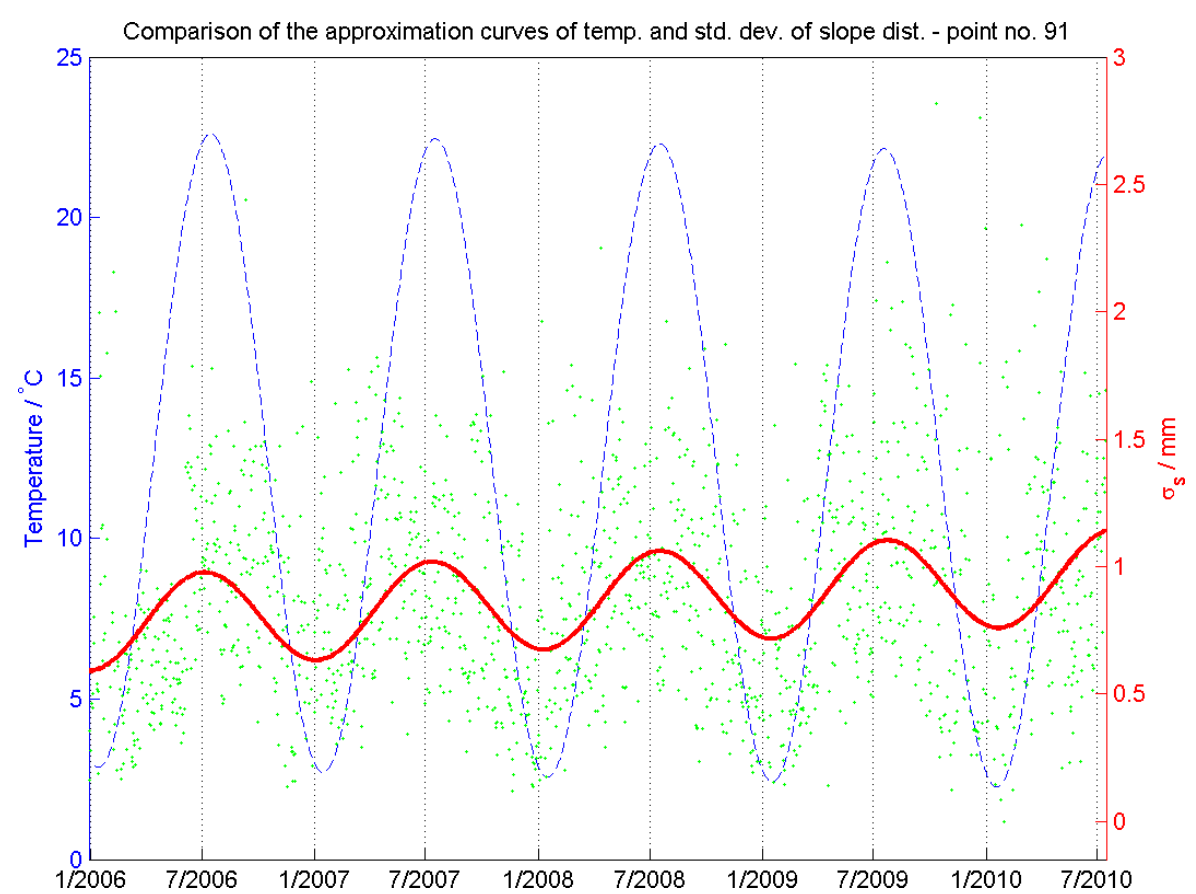

Figure 12. Comparison of the approximation curves of the temperature and the standard deviations of the slope distance - reference point 91.

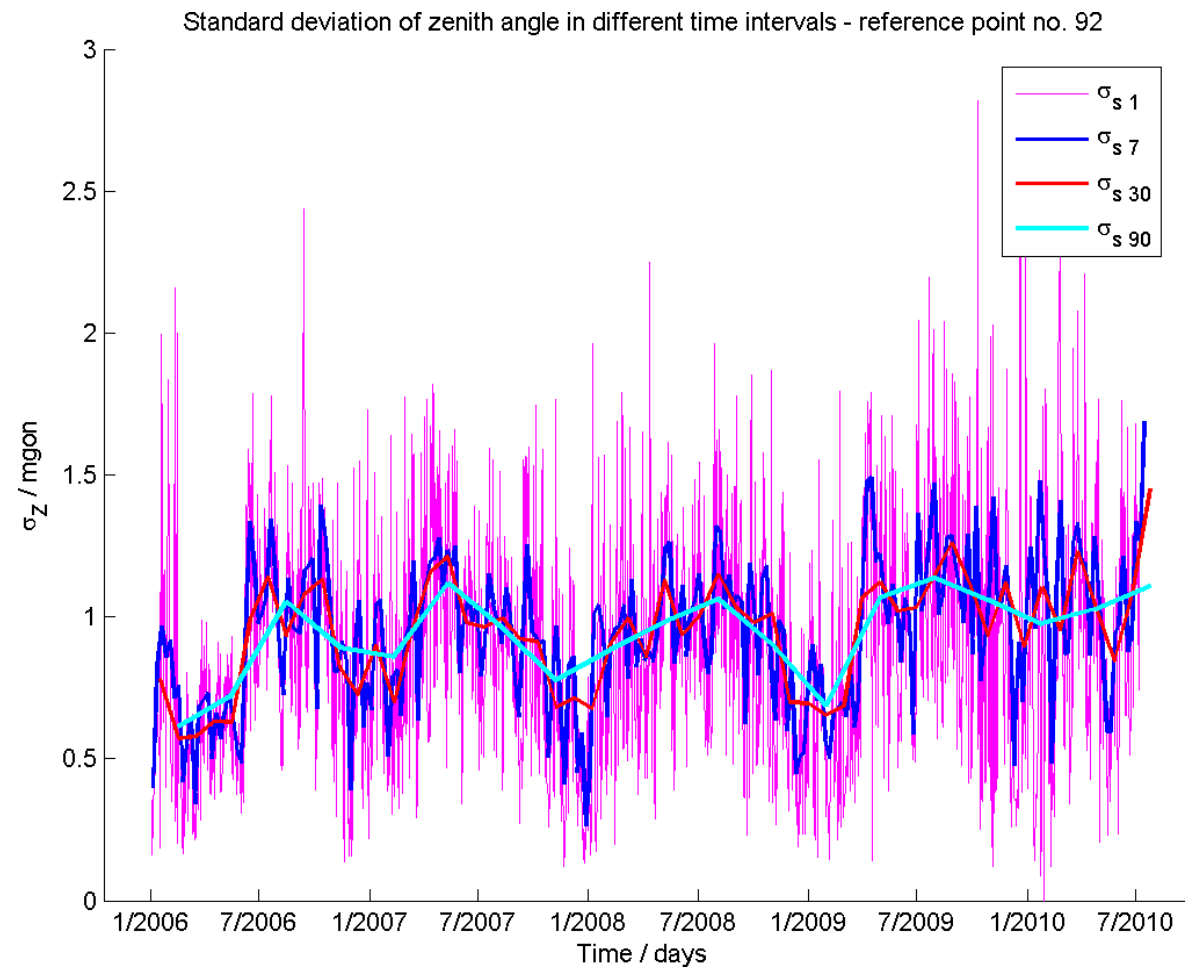

Figure 13. Standard deviations of the slope distance in different time intervals - reference point 91.

\begin{tabular}{lccccc}
\hline & \multicolumn{4}{c}{ Reference point } \\
\cline { 2 - 5 } & $\mathbf{9 1}$ & $\mathbf{9 2}$ & $\mathbf{9 3}$ & $\mathbf{9 5}$ \\
\hline$\overline{\sigma_{s}}$ & {$[\mathrm{~mm}]$} & 1.06 & 1.37 & 0.93 & 0.84 \\
$\min \sigma_{s}$ & {$[\mathrm{~mm}]$} & 0 & 0.09 & 0 & 0.09 \\
$\max \sigma_{s}[\mathrm{~mm}]$ & 3.49 & 4.46 & 5.27 & 3.67 \\
$n$ & 1579 & 1593 & 1610 & 1137 \\
\hline
\end{tabular}

TABLE 9. Average standard deviations of the slope distance and min./max. values. 
analysis for specific reference points. It is clear from the values listed in Table 9 that the average standard deviations correspond to the size of the fixed part of the standard deviation of the slope distance specified by the manufacturer.

\section{Discussions OF THE FINDINGS}

The analysis of the accuracy of the measurements has brought very interesting results. The results of the analysis of the individual variables are often similar, this mainly applies to the horizontal direction and the zenith angle. The most important results are the values of the linear trends, the absolute values of the standard deviation and the dependence of the size of the standard deviation on the air temperature.

In the analysis of the accuracy of the horizontal direction, the average standard deviation of the horizontal direction was determined with the value of 0.66 mgon. This value is higher than the value declared by the manufacturer, but the accuracy is sufficient for the purpose of this monitoring. The calculated standard deviation includes, in addition to the accuracy of the measurement and the accuracy of the automatic target recognition, effect of the surrounding environment (for the consecutive measurements), e. g. the influence of the atmosphere and the changes in optical parameters of the glazing of the shelter.

However, even more important is the fact that the calculated values of the daily standard deviation show a very small linear trend. It is essential for the conclusion that the accuracy of the horizontal direction is constant and it almost does not change in the term of several years.

The values of standard deviation of the horizontal direction change periodically, with the annual period and the average amplitude of $0.1 \mathrm{mgon}$. These periodic changes are most likely caused by meteorological phenomena, specifically an air temperature as it is apparent from a comparison of the approximation curves of the temperature and the standard deviation of the horizontal direction. It can be said that the values of standard deviation are generally higher in the summer than in the winter.

The average standard deviation of the zenith angle was determined with the value of 0.58 mgon in the analysis of the accuracy of the zenith angle. This value is lower by 0.08 mgon than the average standard deviation of the horizontal direction. This is a very good result, because it confirms the manufacturer's claim that the accuracy of the measurement of the horizontal direction and the zenith angle is the same.

Similarly, as in the accuracy of the horizontal direction, the calculated accuracy of the zenith angle also includes an accuracy of the automatic target recognition and other effects of the surrounding environment.

A linear trend of the accuracy of the zenith angle is negligible, as in the case of the accuracy of the horizontal direction. The linear trend is evenly decreasing in the case of the reference point 91 . As it was already described above, very important is a fact that the accuracy of zenith angle is constant throughout the analyzed period.

However, the standard deviation of the zenith angle does not show any changes with significant annual periodic amplitude compared to the accuracy of the horizontal direction. The calculated amplitude is around 400 days. Also, the temperature dependence is not apparent to the standard deviation of the zenith angle. Consequently, it can be assumed that the changes in the air temperature and other atmospheric phenomena do not have an influence on the size of the standard deviation of the zenith angle in the long term.

The last analyzed measured value was the slope distance, for which the average standard deviation was of $1.1 \mathrm{~mm}$. This value of the average standard deviation is a half of the one declared by the manufacturer for these distances. The value of the average standard deviation corresponds to a constant part of the formula for the calculation of the standard deviation of the distance given by the manufacturer. It seems that the part of the formula depending on the distance has no effect in this case. It can be assumed that the accuracy of the automatic target recognition does not apply in the accuracy of the slope distance.

The detected linear trend of the accuracy of the slope distance is very small and it is insignificant in this application of the monitoring. But, in the charts for all reference points, there is a noticeable increase of the number of the standard deviations with a higher value since the half of the 2008. One can infer that the accuracy of the slope distance is getting slightly worse. It is apparent from the charts, but the size is negligible compared to the accuracy of the slope distance. This deterioration may be caused by, for example, wear down of the laser beam source used for measuring lengths and the automatic target recognition. Values of the standard deviation of the slope distance shows annual periodic changes with amplitude of about $0.2 \mathrm{~mm}$. Maximum and minimum of the approximation curve correspond to the seasons. The standard deviations reach higher values in the summer and lower values in the winter. It is clear that the value of the standard deviation of the slope distance is dependent on the temperature of the air.

\section{Conclusions}

The analysis of the measured values by the total station determined the average standard deviations of the horizontal direction (0.66 mgon), the zenith angle (0.58 mgon) and the slope distance $(1,1 \mathrm{~mm})$. Other result of the analysis is very small linear trend of the standard deviations of the all measured values. The value of the standard deviations of the horizontal direction and the slope distance is significantly dependent on the air temperature.

Finally, it can be said that the accuracy of the angle measurements is stable and the accuracy of the slope 
distance is getting slightly worse, but the change is negligible in the analyzed time period. On the one hand, the average standard deviations of the horizontal direction and the zenith angle are almost identical and also higher than the manufacturer declares, on the other hand, the average standard deviation of the slope distance is lesser than the manufacturer declares. The determined standard deviations of the measurements meet the requirements of the accuracy of the monitoring of landslides in the ČSA mine.

\section{LIST OF SYMBOLS}

$l_{i} \quad$ measurement in time $i$ (horizontal direction, zenith angle, slope distance) [gon, m]

$s_{l} \quad$ estimate of the standard deviation of the measurement $l$ [mgon, mm]

$x$ time of measurement in the $\mathrm{L}-\mathrm{H}$ function [day]

$y$ estimate of the measurement in the $\mathrm{L}-\mathrm{H}$ function [gon, m]

\section{ACKNOWLEDGEMENTS}

Supported by grant SGS 2017 - Optimization of acquisition and processing of $3 \mathrm{D}$ data for purpose of engineering surveying, geodesy in underground spaces and laser scanning.

\section{REFERENCES}

[1] R. Urban. Surveying works during the deformation measurement of buildings. First printing. CTU Publishing House, Prague, 2015. ISBN 978-80-01-05786-5.

[2] T. Beran, L. Danisch, A. Chrzanowski, M. Bazanowski. Measurement of deformations by MEMS arrays, verified at sub-millimetre level using robotic total stations. Geoinformatics FCE CTU 12:30-40, 2014. DOI:10.14311/gi.12.6.

[3] Y. G. He, C. J. Zhao. Large-scale bridge distortion measuring technique discussion. International Conference on Mechanics and Civil Engineering (ICMCE), Wuhan, Peoples Republic of China, 2014. DOI:110.2991/icmce-14.2014.120.

[4] A. Berberan, M. Machado, S. Batista. Automatic multi total station monitoring of a tunnel. Survey Review 39(305):203-211, 2007. DOI:10.1179/003962607X165177.

[5] M. Štroner, R. Urban, P. Rys, J. Balek. Prague castle area local stability determination assessment by the robust transformation method. Acta Geodynamica et Geomaterialia 11(4):325-336, 2014. DOI:10.13168/AGG.2014.0020

[6] A. Aryal, B. A. Brooks, M. E. Reid, et al. Displacement fields from point cloud data: Application of particle imaging velocimetry to landslide geodesy. JOURNAL OF GEOPHYSICAL RESEARCH-EARTH SURFACE 117(Article Number F01029), 2012. DOI:10.1029/2011JF002161.

[7] V. Ballu, J. Ammann, O. Pot, et al. A seafloor experiment to monitor vertical deformation at the Lucky Strike volcano, Mid-Atlantic Ridge. JOURNAL OF GEODESY 83(2):147-159, 2009. DOI:10.1007/s00190-008-0248-3
[8] J. Lucic. Monitoring a Cruise Shipwreck. Construction equipment guide, May 2, page 8, 2012. http://www. constructionequipmentguide.com/web_ edit/Southeast/-\%202012/0912/SE00802SE.pdf

[9] C. Tse, J. Luk. Design and implementation of automatic deformation monitoring system for the construction of railway tunnel: A case study in West Island Line. Joint International Symposium on Deformation Monitoring, Hong Kong, China, 2011.

[10] D. Dzurisin, M. Lisowski, C. W. Wicks, et al. Geodetic observations and modeling of magmatic inflation at the Three Sisters volcanic center, central Oregon Cascade Range, USA. JOURNAL OF VOLCANOLOGY AND GEOTHERMAL RESEARCH 150(1-3):35-54, 2006. DOI:10.1016/j.jvolgeores.2005.07.011

[11] L. M. Peci, Berrocoso, R. M., Paez, et al. IESID: Automatic system for monitoring ground deformation on the Deception Island volcano (Antarctica). COMPUTERS \& GEOSCIENCES 48:126-133, 2012. DOI:10.1016/j.cageo.2012.05.004.

[12] W. Stempfhuber. Performance of geodatic monitoring systems. BAUTECHNIK 89(11):794-800, 2012. DOI:10.1002/bate.201201575

[13] B. Klappstein, G. Bonci, W. Maston. Implementation of real time geotechnical monitoring at an open pit mountain coal mine in western Canada. International multidisciplinary scientific symposium UNIVERSITARIA SIMPRO 2014, Petrosani, Romania, 2014.

[14] A. C. Bala, F. M. Brebu, A. M. Moscovici. Using terrestrial laser scanning technologies for high construction monitoring. 12th International Multidisciplinary Scientific Geoconference (SGEM), Albena, Bulgaria, 2012.

[15] M. Scaioni, L. Barazzetti, A. Giussani, et al. Photogrammetric techniques for monitoring tunnel deformation. EARTH SCIENCE INFORMATICS 7(2):83-95, 2014. DOI:10.1007/s12145-014-0152-8.

[16] I. Lipták, J. Erdélyi, P. Kyrinovič, A. Kopáik. Monitoring of bridge dynamics by radar interferometry. Geoinformatics FCE CTU 12:10-15, 2014. DOI:10.14311/gi.12.2.

[17] C. Castagnetti, E. Bertacchini, A. Corsini, A. Capra. Multi-sensors integrated system for landslide monitoring: critical issues in system setup and data management. European Journal of Remote Sensing 46:104-124, 2013. DOI:10.5721/EuJRS20134607

[18] J. Blachowski, S. Ellefmo, E. Ludvigsen. Monitoring system for observations of rock mass deformationscaused by sublevel caving mining system. Acta Geodynamica et Geomaterialia 8(3):335-344, 2011.

[19] v. Nestorović. On the precision of measuring horizontal directions in engineering projects. Geonauka 3(1):33-40, 2013. DOI:10.14438/gn.2013.22

[20] T. Owerko, M. Strach. Examining coherence of accuracy tests of total station surveying and geodetic instruments based on the comparison of the results of the complete test procedures according to ISO 17123. Reports on Geodesy 87(2):291-299, 2009. 
[21] P. Stanislav, J. Blín. Technical support of the service of automatic total station Leica TCR 2003A in operating conditions of the company Mostecká uhelná a.s. Acta Montanistica Slovaca 12(Special Issue 3/2007):554-558, 2007. ISSN 1335-1788.

[22] M. Štroner, M. Hampacher. Processing and Analysis of Measurements in Engineering Surveying. First printing. CTU Publishing House, Prague, 2011. 